International Journal of Instruction e-ISSN: 1308-1470 • www.e-iji.net
July $2018 \bullet$ Vol.11, No.3

p-ISSN: 1694-609X

pp. $463-476$

Received: $27 / 02 / 2018$

Revision: $16 / 04 / 2018$

Accepted: 20/04/2018

\title{
Multiple Strategies Approach and EFL Reading Comprehension of Learners with Dyslexia: Teachers' Perceptions
}

\author{
Ghada Awada \\ Ph.D., American University of Beirut, Lebanon, ghadaawada@gmail.com
}

\section{Mar Gutiérrez-Colón Plana}

Ph.D., Universitat Rovira i Virgili, Spain, mar.gutierrezcolon@urv.cat

The present study reports the perceptions that the teachers have of the usefulness of a combined strategy instruction for the improvement of the reading comprehension skill in students with dyslexia. These students are placed in regular classes on a full-time basis (inclusion) and their situation has not been changed for the purpose of this study. The strategy instruction includes graphic organizers, visual displays, mnemonic illustrations, movie maker journaling and movie use, prediction, inference, text structure awareness, main idea identification, summarization, and questioning. The findings of the qualitative analysis indicate that all those strategies help students improve the reading comprehension of narrative texts. However, teachers explain that each strategy has positive aspects as well as drawbacks. This study will help teachers to design appropriate syllabus as well as sets of activities to groups of students in inclusive settings.

Keywords: Dyslexia, English as a foreign language, reading comprehension strategies, inclusive model, Lebanese schools, teacher perception

\section{INTRODUCTION}

Over the past 15 years, a plethora of research has been conducted on the reading process, which resulted in empirical and theoretical findings with significant implications for sound and effective classroom practices and applications. Many of the research studies have contributed significantly to build a knowledge base and repertoire of instructional strategies designed to improve comprehension. Moreover, such reading comprehension interventions have indeed generated remarkable gains in reading for students with learning disabilities (Vaughn, Levy, Coleman \& Bos, 2002).

\section{CONTEXT AND REVIEW OF LITERATURE}

Inclusion can be defined as the placement of learners with reading difficulties in regular classes on a full-time basis (Sapon-Shevin, 1996), whereas integration demands placing the learners on part-time basis with typically developing peers (Bunch, Finnegan,

Citation: Awada, G., \& Gutiérrez-Colón, M. P. (2018). Multiple Strategies Approach and EFL Reading Comprehension of Learners with Dyslexia: Teachers' Perceptions. International Journal of Instruction, 11(3), 463-476. https://doi.org/10.12973/iji.2018.11332a 
Humphries, Doré \& Doré, 2005). Inclusion and exclusion are inseparably connected, since inclusion can take place only after overcoming the pressures towards exclusion (Booth, Ainscow \& Dyson, 1997), since exclusion is considered a sanction (Jull, 2008).

Reading comprehension is extremely challenging for learners with dyslexia and reading difficulties, since many teachers emphasize that comprehending written texts might be the foremost objective of reading (Edmonds, Vaughn, Wexler, Reutebuch, Cable, Tackett and Schnakenberg, 2009). Comprehension strategy instruction is vital for helping students comprehend the purpose of reading and for equipping learners with the real-world skills, which are necessary for understanding text (Hoenig, Sim, Bochev, Herrberger \& Kiefer, 2008).

The teacher plays a major role in establishing successful inclusive learning environments, which facilitate and promote learning for the learners with reading difficulties since the created inclusive environments enormously rely on the presence of teacher's knowledge, skills, attitudes, values, cooperation, and expertise. As such, educators' perceptions of inclusion and awareness of the hindrances are crucial in order to create the inclusive learning environments (Hoenig et al., 2008). Students with reading difficulties usually have serious difficulties in understanding text patterns and not being able to recognise the text structure, which impedes the retrieval of content information (Englert \& Thomas, 1987). Characterized as passive readers (Torgesen, 1982), learners with reading difficulties might not employ the most common reading comprehension strategies to comprehend information in texts, which doesn't allow them to control and evaluate their understanding of text.

Research indicates that learners with reading difficulties have different learning profiles characterized by: scanty recall or identification of main ideas and supporting details (Baumann, 1984; Warren \& Fitzgerald, 1997), difficulties in drawing inferences (Holmes, 1985), not being able to connect new information to prior knowledge (Johnson, Graham \& Harris, 1997), and impossibility at monitoring their comprehension (Wong, Butler, Ficzere, \& Kuperis, 1996). Awada \& Gutiérrez-Colón (2017) conducted a research in which a combined strategy instruction was implemented in order to enhance the comprehension of narrative and expository texts for learners with dyslexia. This former study contributes to the existing literature as there are few studies that investigate the effect of reading interventions (Suggate, 2016) since the focus has always been on individualized instruction given to learners with reading difficulties (Goodwin \& Ahn, 2013)

In this study, we analyse the perceptions that the teachers have of the usefulness of a combined strategy instruction for the improvement of the reading comprehension skill in students with dyslexia. These students are placed in regular classes on a full-time basis (inclusion) and their situation has not been changed for the purpose of this study.

\section{Reading Strategies Used In The Experiment}

In this section, a brief description of the strategies used in this research is presented. 
Graphic Organizers: Hanjani \& Shafiei (2017) asserted the effectiveness of graphic organizers on improving the reading comprehension of Iranian EFL Learners. Snyder (2012) and Ausubel (1963) emphasized that the use of graphics could develop, strengthen, and facilitate the occurrence of learning because this strategy could provide learners with a significant framework for associating their prior knowledge with the new information. Kossack \& Hoffman (1987), Nichols \& Rupley (2004), Minaabad (2017) and Minskoff \& Allsopp (2003) stated that graphic organizers enhance the reading comprehension of students with dyslexia.

Visual Displays: The visual displays could improve the reading comprehension of a text, since teachers could model the process of making visual images of a word, paragraph, or a text, so the students could create images, which represent the information in the reading passage (Bell, 1991; Miller 2004).

Mnemonic Illustrations: According to Mastropieri, Scruggs \&amp; Whedon (1997), Mastropieri \&amp; Scruggs (1994), mnemonic illustrations could give the students an ability to use strategies that would enable them to pre-plan and organize tasks. The learners could use mnemonic illustrations to recall difficult words and to formulate difficult ones as well.

Movie Maker journaling and movie use: According to Awada (2014), and Lee and Vail (2005), computer devices ought to meet the needs of the individual in the school environment in a manner that they are used and utilized by the learners and the teachers. The computer exercises entail the Windows Movie Maker journaling, which '...proved to be more effective than the traditional pen and paper journaling in enhancing proficiency and decreasing writing apprehension' ( Awada, 2014, p.36).

Inference: Inference could be defined as the associations individuals could form when they attempt to interpret texts (Nassaji, 2004). Inference could be one of the main cognitive processes in reading comprehension. Inference could enable learners to go beyond what is explicitly stated to deduce implicitly what is missing (Wyver, Markham \& Hlavacek, 2000).

Prediction: The basic techniques of reading are skimming, scanning, extensive and intensive reading (Grellet, 1981). The researchers have added that reading includes several sub-skills: the basic ones are "recognizing the script of a language", inferring the meaning and use of unfamiliar lexical items, understanding "explicitly stated information", and information implicitly mentioned. Reading is an activity involving "predictions", "previewing", and "anticipation" (p.4). Grellet (1981) also mentioned that the aim of prediction is to train the students to make "guesses when reading a text", and indicates that the more students look forward to reading and anticipate in their minds what the text could hold in store for them, the easier it would be to comprehend the basic points of the passage" (p.62).

Text Structure Awareness: Text structures are a way to measure and rate students' reading achievement of the expository texts. These strategies unfold the text structure awareness and lead to a constant and progressive improvement in reading skill (Pedrotty, Ugel, Thompson \& Hamff, 1999; Rivera \& Smith, 1997; Bos \& Vaughn, 
2002; ). The use of the authentic texts would help students integrate academic study and real-world work experience. Such texts would make students gain more life experience; they become more likely to consider learning as an internal experience based process as indicated by Saljo (1979).

Main Idea Identification: Main Idea Identification might be a vital strategy to understand the main ideas (Manset-Williamson \& Nelson, 2005). Learners with dyslexia might have good oral language skills, so they could understand the main ideas of a text although they are challenged with decoding problems. As such, learners with dyslexia might obtain lower scores on reading comprehension tests than on listening comprehension due to decoding and accuracy problems (Grigg, Moran, \& Kuang,, 2010).

Summarization: Jitendra Jitendra, Hopes, and Xin, (2000) demonstrated that summarization strategy could improve the reading comprehension of learners as summarizing gives learners the opportunity to identify the ideas of a text.

Questioning: Questioning could be an important strategy for those students who had a history of reading comprehension difficulties. Furthermore, questioning and paraphrasing could be useful to improve the reading comprehension of learners (Beck, McKeown, Sandora, Kucan, \& Worthy, 1996).

\section{METHOD}

In this study, the learners with reading difficulties are placed in regular classes (inclusive model), so special education support and help are given inside the regular classroom.

\section{Design of the research}

The 16 participating teachers were university graduates holding a minimum of B.A. in English language. Their teaching experience ranged between 5 to 15 years. The teachers attended six training sessions given in collaboration with the Ministry of Education and Higher Education in Lebanon concerning the activities that had to be implemented in inclusive classrooms and covering the strategies that are the object of this study. The teachers were randomly sampled from both private and public schools of Beirut (Lebanon), and they taught students of 7th, 8th, and 9th grades (12-14, 13-15, and 1416-year-old).

Those students who were labelled as dyslexic were done so after taking the test: Dyslexia Identification Checklist. After this diagnosis, the students sat for a second test, supervised by specialists, to double-check this diagnosis. Only those who received a second confirmation took part in this study.

Once the literature was analysed, it was decided to apply different strategies in the experiment: graphic organizers, visual displays, mnemonic illustrations, Movie Maker journaling and movie use, inference, prediction, text structure awareness, main idea identification, summarization, and questioning. According to the literature review, in order to achieve positive results, the strategies are never applied in isolation. It was 
decided to apply these strategies during different sessions and within different types of activities, but always making sure that during these weeks all ten strategies were used in a similar amount of time and number of activities designed beforehand by the teachers. The treatment lasted for 10 weeks at a rate of 6 hours a week, and each strategy was employed 2-3 times a week.

\section{Data collection tools and Sampling technique}

Writing logs, which expressed the perceptions of the participating teachers, were collected over a period of ten weeks and the content was analysed thematically. The categories of analysis were predetermined a priori based on the list of the strategies. Data pertaining to each strategy were unitized and sub-categorized into idea units. These units were used to write up the study results eliciting teachers' perceptions of the efficacy and usefulness of the employed strategies.

The semantic analysis of the reflection logs given by the teachers led to the emergence of the themes, which formed the basics of the qualitative data reported. The teachers' observations noted during the period of the instruction and the quantitative data collected from the reading items and reading responses corrected by three teachers enabled teachers to write the writing logs.

The recurrent themes that emerged from the semantic analysis of all the 16 teachers' reflection logs yielded the qualitative study data.

\section{Validity of the Instruments}

The tests in this study enable the teachers to judge students' abilities to organize, integrate, interpret material, and express themselves in their own words. Due to these tests, the teachers can comment on students' progress, about the quality of their thinking, and the difficulties they might have had during the learning process. These tests follow the standardized test format as adopted by the Special Educational Center for Research and Development of the U.S. Department of Education. Therefore, these tests use uniform procedures for administration and scoring in order to assure that the results from different students will be comparable.

\section{FINDINGS}

As indicated earlier, the teacher reflection logs were used as tools to collect qualitative data regarding their perceptions of the problems and prospects using the various instructional techniques that constituted combined strategy instruction. After using the combination of strategies with their students, they had to rate their experience and evaluate each of them: Were these strategies effective to learn English for students with dyslexia? Did they think they were a drawback? The content analysis of the reflection logs gathered from the 16 participating teachers was categorised in terms of the strategies, and the results are presented in table 1. 
Table 1

Teachers' Perceptions of Strategies' Effectiveness and Drawbacks

\begin{tabular}{lll}
\hline Strategy & Effectiveness & drawbacks \\
\hline Graphic organiser & 86.25 & 22.5 \\
\hline Visual displays & 87.5 & 22.5 \\
\hline Mnemonic illustrations & 55 & 45 \\
\hline Movie maker journaling and movie use & 100 & 33.75 \\
\hline Predicting & 93.75 & 11.25 \\
\hline Inference & 56.25 & 43.75 \\
\hline Structure awareness & 62.5 & 37.5 \\
\hline Main idea identification & 68.75 & 31.25 \\
\hline Summarization & 50 & 50 \\
\hline Questioning & 100 & 11.25 \\
\hline
\end{tabular}

Graphic Organizers

Fifteen teachers $(86.25 \%)$ considered graphic organizers as useful and helpful for the students to think logically about a concept as well as effective to understand the ideas, recall content, understand instructions, and help students summarise the content and construct meaning. They also considered graphic organizers to help students understand the relationship between various pieces of information they otherwise failed to identify. Finally, teachers commented that graphic organizers are useful to make students understand abstract concepts.

Yet, it should be also noted that two teachers $(22.5 \%)$ considered graphic organizers as a technique, which also has disadvantages. According to their class experience, some graphs might confuse student's more than verbal explanations. They thought that the lack of note taking might affect the students' performance. A teacher $(11.25 \%)$ found graphic organizers ineffective except to outlining the main ideas; another wrote about the simplification of the story (story map) as something negative, because he felt that some meaning was lost when using this technique. In addition, a teacher pinpointed that graphic organizers made students link ideas in a wrong way, and for this reason, the students missed the story.

Visual Displays

According to fourteen teachers (87.5\%), visual displays were an excellent hook to get the audience attention; teachers perceived that visual displays could allow for more retention of the meaning as they motivated students with the content, motivated teachers to teach, and motivated struggling readers. Teachers stated that images seemed easier to recall than words and when associated with a specific meaning, images seemed to be stored in the long-term memory more easily than words or concepts and widened the imagination of students as well as helped the students synthesize information.

Conversely, two teachers $(22.5 \%)$ highlighted the drawbacks of the use of the visual displays as follows: They thought that visual displays were time consuming to prepare, distracting and thus impeding the understanding of concepts. A visual aid with the wrong information could cause a distraction and detract from the message the image was supposed to convey. Images were difficult for those students who were not visual 
learners; they were more suitable for children. They caused some of the audience to focus solely on the screen; they were ineffective because memorizing the picture meant that the details of the content were lost.

\section{Mnemonic Illustrations}

The following expressions summarise the opinion of the teachers regarding this technique. Tweleve teachers $(55 \%)$ thought that mnemonic illustrations could form an effective link between the stimulus and response while improving the memory. They enhance the imagination and help learners recall information in a more holistic way. Teachers also believed that they are useful for acquiring difficult vocabulary; they involve linking unfamiliar with familiar information along with the use of a simple visual picture or letter/word combination.

However, four teachers (45\%) also talked about drawbacks; two teachers $(22.50 \%)$ indicated that students need much time to create, learn and practice; two teachers $(22.50 \%)$ asserted that overuse can result in confusion; two teachers $(22.5 \%)$ emphasized that students must practise the Mnemonic Illustrations in a precise manner; therefore, students might get tired of them; three teachers indicated that this technique requires time and resources by the instructors to develop creative and effective outcomes.

Movie Maker Journaling And Movie Use

Sixteen teachers $(100 \%)$ believe that Movie maker journaling and movie use enhanced reading because students found working with computers something common in their life, and they preferred reading and writing using screens. Teachers observed that there was social interaction, which is sometimes difficult to be attained by students with dyslexia. They also referred to Movie maker journaling and movie use as fast and helpful technique in the process of instruction; stories read or created using Windows Movie Maker (WMM) were remembered more easily than those on paper. Moreover, a significant boost in learners' creativity was demonstrated when students were asked to use the Windows live Movie Maker (WLMM) to create their own stories. This last perception of the teachers coincides with the conslusions of a former research conducted by Awada (2014, ).

Nevertheless, this strategy also got some negative comments by three teachers $(3.75 \%)$ : Movie maker journaling and movie use were not easy to use; two teachers $(22.5 \%)$ felt they did not have much experience in working with computers; Movie maker journaling and movie use were time consuming and sometimes distracting to students if not well oriented and monitored. Feedback was not accurate; sometimes the WMM activities were too long and had too many things to pay attention to, but students needed time to get used to those types of activities. One teacher asserted that WMM journaling and movie use made the students forget how to take notes. Students had to do the WMM activities at home; therefore, the WMM activities could also be isolating.

Inference

Nine teachers $(56.25 \%)$ found this strategy helpful for students from the cognitive point of view it made students critical thinkers. Teachers also considered that this strategy was 
effective because it meant not only to be able to "read between the lines" but also to know and understand the hidden meanings of the text or to draw one's own personal conclusion about a text. Teachers reported the advantages as follows: a better overall comprehension, more engagement with the text.

Yet, other teachers $(43.75 \%)$ expressed negative remarks about this technique. They said that inference questions were often so narrow in relation to the question that they created or magnified bias that was not factored into the survey. With this type of questioning, one might understand the text in a different way from what the text implied; sometimes, they made students feel lost and annoyed by the way they were asked; inference was effective but challenging and demanding as well.

\section{Prediction}

Prediction is a strategy that got many positive reflection logs. The comments were as follows: Fifteen teachers $(93.75 \%)$ emphasized that prediction stimulated students' minds, made them active readers and helped them understand the reading material in a better way. Prediction ensured the involvement and participation of all students, developed students' critical thinking and motivation, enhanced their imagination, and improved their creativity. Prediction was useful in activating prior knowledge, guiding practice, and arousing students' curiosity before reading any text or story. Prediction grabbed students 'attention by creating a sense of competitive atmosphere among students. The strategy put the readers in the general atmosphere of the story as it was a lively exercise, which could be very good in spreading competitive spirit among students. Furthermore, prediction reflected students' prior knowledge of the topic, enhanced students' imagination as well as improved their creativity. One teacher $(11.25 \%)$ asserted that the only drawback of prediction was the great amount of time and the practice students might waste while providing incorrect feedback to other students.

\section{Text Structure Awareness}

Ten participating teachers $(62.5 \%)$ tended to consider this strategy as important to help students understand the meaning of texts, mainly because teaching structures not only helped students understand them but also enabled them to produce texts with similar features. Students could identify the text structure and could cover more material in shorter time. Awareness of text structure made students more accountable for listening and taking notes. This strategy helped students use the suitable verb tenses, organise their own ideas and create their own texts.

Nevertheless, a $37.5 \%$ of the teachers expressed negative feelings. They believed that: text structure is not important to improve the understanding of the text; the awareness of text features is not needed at a lower level; teaching the structure of texts can be frustrating and too challenging for the teachers, for it might limit thinking, confine focus to structure and hinder analysis.

Main Idea identification

Eleven of the participating teachers $(68.75 \%)$ in the present study considered the identification of the main idea technique to be both useful and important, as well as 
helpful in identifying the authors' purpose; it helped the students focus on the key points. This strategy also helped finding the link between the introduction of the text, the title and the background knowledge.

However, five teachers $(31.25 \%)$ indicated some drawbacks; if the students did not identify the main idea, they could get lost in the paragraph. It might discourage students with dyslexia to read since they found it difficult; it limited their understanding; sometimes, focusing on a main idea did not give students a clear view of what the meaning of text is.

\section{Summarization}

Eight of the participating teachers $(50 \%)$ considered the summarization technique "a must" for learners. Teachers agreed that this strategy could help students determine the parts of the text that were important and the ones that were not, and to check what they had understood of what they had read. A summary could help students check their ability to select the most important information of a text; it was an effective tool for assessment; it helped students determine the most important parts of the story as well as main ideas and key words of a text.

However, eight teachers $(50 \%)$ found this strategy to be not so useful. The main reasons were that they found the technique, as time consuming and difficult as it ignored details that were important for students with dyslexia.

Questioning

The participating teachers $(100 \%)$ mainly described the questioning technique as encouraging for class discussion and a good technique to improve oral fluency. They found that this strategy made students interactive readers; they found that it was a very useful strategy which had several advantages such as checking on learning, encouraging participation, class discussion, and improving oral fluency; they also said that it enhanced comprehension; it allowed for clarification and consolidation of learning.

Yet, it should be noted that one teacher $(11.25 \%)$ described the question-answer as a non-effective strategy for students with dyslexia and again, as a time-consuming strategy.

\section{DISCUSSION}

The findings of the qualitative data, resultant from the analysis of the reflection logs given by the teachers of the study, indicate that each of the reading strategies used in the present study is effective in a specific aspect of the process of reading and understanding what is being read. The strategies of graphic organizers, prediction, inference, main idea identification, summarization and questioning have been the easiest to implement by the teachers.

Movie maker journaling and movie use and graphic organizers are so effective as they increased students' motivation and ensured full engagement in the discussed narrative texts. Most teachers added that WMM made it possible for students with dyslexia who struggle with handwriting to finalize neat printed work. Yet, the WMM strategy might not be practical for some teachers due to time constraints and unavailability of 
equipment. The findings of the present study align with those of Awada (2014) that asserted the efficacy of the WMM in increasing students' motivation and improving their writing skills. This finding of the study endorses those of Hanjani \& Shafiei (2017), Minaabad (2017) and Minskoff \& Allsopp (2003) that indicated that graphic organizers enhance the reading comprehension of students with dyslexia. Furthermore, the findings of the study corroborate those of Awada \& Gutiérrez-Colón (2017) that asserted that "Combined strategy instruction in the field of the inclusion theory is more effective than regular instruction in improving reading comprehension of both students with and without dyslexia when using narrative texts (grades 7 and 8) in the classroom" (p.10). The findings of the study also support those of Bell (1991); Miller (2004); Mastropieri et al., (1997); Grellet (1981); Manset-Williamson \& Nelson (2005); Jitendra et al., (2000); Beck et al.,(1996) that asserted the effectiveness of respectively visual displays, mnemonic illustrations, prediction, main idea identification, summarization and questioning in improving the reading comprehension of learners with reading difficulties.

The two most important characteristics that make reading comprehension a difficult activity for learners with dyslexia, is the difficulty in decoding words and thus, learning new vocabulary, and therefore, they tend to ignore the content when reading, which makes reading comprehension a specially complex activity.

From the results of the analysis, we have learnt that some of the strategies used in this study are especially helpful in the decoding of the meaning: Graphic organizers enabled students to think logically about the concept and link different pieces of information. By doing this, the students could find a relation among the different bits of information. However, we also found that some graphs confused students' more than verbal explanations and we believe that this is an important that this aspect is taken into account. Visual displays could allow for more retention of the meaning; for this reason, most teachers considered this strategy very useful to ve used with students with dyslexia. As for mnemonic illustrations, they allowed students to visualize abstract ideas, which was sometimes impossible with words; however, not all ideas/concepts could be presented visually, and teachers reported having had many difficulties in applying them in class. The qualitative data for Movie maker journaling and movie use indicates that students liked using computers in class, and they enjoyed reading on screens. This strategy enhanced social interaction, which is a very positive aspect to take into consideration. Prediction helped them develop analytical thinking and conceptual access before sensory exposure; however, this strategy was not useful and even distressing when reading about real-life situations. Concerning inference, teachers believed this strategy could develop critical and analytical thinking and allow for conceptual access in wider context as well as awareness of multiple meanings/applications of concepts/ideas. Teachers' feedback towards the awareness of the text structure strategy indicated that knowing the text genre would mean understanding the structure, language use, style, etc. However, they thought that it might limit thinking and confine focus to structure instead of analysis, therefore it was thought that it might be a too complex strategy for students with dyslexia. . Regarding main idea identification, teachers indicated that this strategy should be used after reading the title or author's background, if available, to create 
expectations about content. Summarization was defined as a good strategy for focusing on what was most important and to help students express in their own words; Finally, the questioning strategy could encourage discussion; however, it could demand much focus on providing correct answers to satisfy the teacher.

\section{CONCLUSION}

The study reports the analysis of the class experience of 16 teachers who noted their perceptions of the use of combined strategy instruction consisting of different strategies employed to improve the EFL reading comprehension of learners with dyslexia. The 16 teachers gave instruction to learners with dyslexia provided with inclusive environments.

It can be concluded that the use of the combined strategy instruction could help students. However, the sampled teachers indicated that each strategy has its positive aspects as well as drawbacks. The data gathered also indicate that there is no single best approach or strategy for overcoming the challenges that hinder the reading comprehension skills of learners with dyslexia. The treatment should be a combination of strategies and techniques that are implemented for a long period, and carefully administered to ensure the ongoing observation of the reaction of the students and the feedback of teachers. This study will help teachers and policy makers to design appropriate syllabus as well as sets of activities for groups of students in inclusive settings.

It is important to note that this study is one of the few studies conducted in Lebanon to elicit teachers' perceptions of the reading comprehension combined strategy instruction after providing the teachers with the needed training and ensuring the conditions of the inclusive environments. However, the small number of subjects is a major limitation in the present study. Another limitation is that the student outcomes were not assessed by one valid measure as students diagnosed initially with dyslexia were referred to different specialists and not to the same specialists to confirm or disconfirm the assessment. Further studies at larger scales and involving more grade levels are recommended to validate the generalization of the present study findings.

\section{REFERENCES}

Ausubel, D., (1963). The Psychology of Meaningful Verbal Learning. New York: Grune and Stratton

Awada, G., (2014). Relative Impact of Windows Movie Maker. Journaling on Writing Proficiency and Apprehension. AWEJ; 5(3), 31-44. 2014.

Awada, G. M., \& Gutiérrez-Colón, M. (2017). Effect of Inclusion Versus Segregation on Reading Comprehension of EFL Learners with Dyslexia: Case of Lebanon. English Language Teaching. 10(9), 49.

Baumann, J.F. (1984). The effectiveness of a direct instruction paradigm for teaching main idea comprehension. Reading Research Quarterly, 20(1), 93-115 DOI: $10.2307 / 747654$ 
Beck, I. L., McKeown, M. G., Sandora, C., Kucan, L., \& Worthy, J. (1996). Questioning the author: A yearlong classroom implementation to engage students with text. The Elementary School Journal, 96(4), 385-414. https://doi.org/10.1086/461835

Bell, N. (1991). Gestalt imagery: A critical factor in language comprehension. Annals of Dyslexia, 41(1), 246-260.

https://link.springer.com/article/10.1007\%2FBF02648089?LI=true

Booth, T., Ainscow, M., \& Dyson, A. (1997). Understanding inclusion and exclusion in the English competitive education system. International journal of inclusive education, 1(4), 337-355. http://dx.doi.org/10.1080/1360311970010404

Bos, C. S., \& Vaughn, S. (2002). Strategies for teaching students with learning and behavior problems. Allyn and Bacon, A Pearson Education Company, 75 Arlington Street, Boston, MA 02116.

Bunch, G., Finnegan, K., Humphries, C., Doré, R., \& Doré, L. (2005). Finding a way through the maze: Crucial terms used in education provision for Canadians with Disabilities. Toronto, ON, Canada: The Marsha Forest Centre

Cole, B. A. (2005). Mission impossible? Special educational needs, inclusion and the re-conceptualization of the role of the SENCO in England and Wales. European Journal of Special Needs Education, 20(3), 287-307. http://dx.doi.org/10.1080/08856250500156020

Edmonds, M. S., Vaughn, S., Wexler, J., Reutebuch, C., Cable, A., Tackett, K. K., \& Schnakenberg, J. W. (2009). A synthesis of reading interventions and effects on reading comprehension outcomes for older struggling readers. Review of educational research, 79(1), 262-300. https://doi.org/10.3102/0034654308325998

Englert, C. S., \& Thomas, C. C. (1987). Sensitivity to text structure in reading and writing: A comparison between learning disabled and non-learning-disabled students. Learning Disability Quarterly, 10, 93-105. https://doi.org/10.2307/1510216

Goodwin, A. P., \& Ahn, S. (2013). A meta-analysis of morphological interventions in English: Effects on literacy outcomes for school-age children. Scientific Studies of Reading, 17(4), 257-285. http://dx.doi.org/10.1080/10888438.2012.689791

Grellet, F. (1981). Developing Reading Skills. Cambridge: Cambridge University Press.

Grigg, W., Moran, R., \& Kuang, M. (2010). National Indian Education Study--Part I: Performance of American Indian and Alaska Native Students at Grades 4 and 8 on NAEP 2009 Reading and Mathematics Assessments. NCES 2010-462. National Center for Education Statistics.

Hanjani, A. M., \& Shafiei, E. (2017). The Effect of Graphic Organizers on Reading Comprehension of Iranian Efl Learners: With a Focus on Gender. Modern Journal of Language Teaching Methods, 7(3), 116. 
Hoenig, K., Sim, E. J., Bochev, V., Herrnberger, B., \& Kiefer, M. (2008). Conceptual flexibility in the human brain: dynamic recruitment of semantic maps from visual, motor, and motion-related areas. Journal of Cognitive Neuroscience, 20(10), 17991814. doi: 10.1162/jocn.2008.20123

Holmes, B. C. (1985). The Effects of a Strategy and Sequenced Materials on the Inferential-Comprehension of Disabled Readers. Journal of Learning Disabilities, 18(9), 542-546. https://doi.org/10.1177/002221948501800909

Jitendra, A. K., Kay Hoppes, M., \& Xin, Y. P. (2000). Enhancing main idea comprehension for students with learning problems: The role of a summarization strategy and self-monitoring instruction. The Journal of Special Education, 34(3), 127139. https://doi.org/10.1177/002246690003400302

Johnson, L., Graham, S., \& Harris, K. R. (1997). The effects of goal setting and selfinstruction on learning a reading comprehension strategy: A study of students with learning disabilities. Journal of Learning Disabilities, 30(1), 80-91. https://doi.org/10.1177/002221949703000107

Jull, S.K. (2008). Emotional and behavioural difficulties (EBD): the special educational need justifying exclusion. Journal of Research in Special Educational Needs, 8 (1). doi: 10.1111/j.1471-3802.2008.00097.x

Kossack, S., \& Hoffman, E. (1987). A Picture's Worth a Thousand Words: Comprehension Processing via the Comics. Journal of Reading, 31(2), 174-176. http://www.jstor.org/stable/40029832

Lee, Y. \& Vail.C.O. (2005). Computer-based reading instruction for young children with disabilituies. Journal of Special Education Technology 20 (1).5-17 https://doi.org/10.1177/016264340502000101

Manset-Williamson, G., Nelson, J.M. (2005). Balanced, strategic reading instruction for upper-elementary and middle school students with reading disabilities: A comparative study of two approaches. Learning Disability Quarterly, 28, 59-74. Google Scholar, Link.

Mastropieri, M.A.; Scruggs, Th.E.; (1994).The Construction of Scientific Knowledge by Students with Mild Disabilities, 28(3); Sage Journals.

Mastropieri, M.A.; Scruggs, Th.E.; Whedon, C.M.S. (1997). Using Mnemonic Strategies to Teach Information about U.S. Presidents: A Classroom-Based Investigation. Learning Disability Quarterly, 20(1). Sage Journals. Miller, J. D. (2004). Public understanding of, and attitudes toward, scientific research: What we know and what we need to know. Public Understanding of Science, 13(3), 273-294. https://doi.org/10.1177/0963662504044908

Minaabad, M. S. (2017). Study of the Effect of Dynamic Assessment and Graphic Organizers on EFL Learners' Reading Comprehension. Journal of Language Teaching and Research, 8(3), 548-555. 
Minskoff, E., \& Allsopp, D. (2003). Academic Success Strategies for Adolescents with Learning Disabilities and ADHD. Brookes Publishing Co., PO Box 10624, Baltimore, MD 21285-0624

Nassaji, H., (2004). The Relationship between Depth of Vocabulary Knowledge and L2 Learners' Lexical Inferencing Strategy Use and Success. The Canadian Modern Language Review, 61 (1), 107-134.

Nichols, W. D., \& Rupley, W. H. (2004). Matching instructional design with vocabulary instruction. Reading Horizons, 45(1), 55. http://www.wmich.edu/coe/spls/readinghorizons/index.htm

Pedrotty, D., Ugel, N., Thompson, S., \& Hamff, A. (1999). Instructional strategies for content-area reading instruction. Intervention in School and Clinic, 34(5), 293-302. https://doi.org/10.1177/105345129903400506

Rivera, D.P. \& Smith, D.D. (1997). Teaching Students with Learning and Behaviour Problems. (3rd ed.) Boston: Allyn and Bacon.

Saljo, R. (1979) Learning from the Learner's Perspective. I: Some Common Sense Conceptions (Rep. No. 76). Goteborg, Sweden: University of Goteborg. Institute of Education.

Sapon-Shevin, M. (1996). Full inclusion as disclosing tablet: Revealing the flaws in our present system. Theory into practice, 35(1), 35-41. https://doi.org/10.1080/00405849609543699

Snyder, A. E. (2012). The Effects of Graphic Organizers and Content Familiarity on Second Graders' Comprehension of Cause/Effect Text. Columbia University.

Suggate, S. P. (2016). A meta-analysis of the long-term effects of phonemic awareness, phonics, fluency, and reading comprehension interventions. Journal of learning disabilities, 49(1), 77-96. DOI:10.1177/0022219414528540

Torgesen, J. K. (1982). The learning-disabled child as an inactive learner: Educational implications. Topics in Learning and Learning Disabilities.

Vaughn, S., Levy, S., Coleman, M., \& Bos, C. S. (2002). Reading instruction for students with LD and EBD: A synthesis of observation studies. The Journal of Special Education, 36(1), 2-13. https://doi.org/10.1177/00224669020360010101

Warren, L., \& Fitzgerald, J. (1997). Helping parents to read expository literature to their children: Promoting main-idea and detail understanding. Literacy Research and Instruction, 36(4), 341-360. http://dx.doi.org/10.1080/19388079709558248

Wyver, S. R., Markham, R., \& Hlavacek, S. (2000). Inferences and word associations of children with visual impairments. Journal of Visual Impairment and Blindness, 94(4), 204-217.

Wong, B. Y., Butler, D. L., Ficzere, S. A., \& Kuperis, S. (1996). Teaching low achievers and students with learning disabilities to plan, write, and revise opinion essays. Journal of learning disabilities, 29(2), 197-212. https://doi.org/10.1177/002221949602900209 